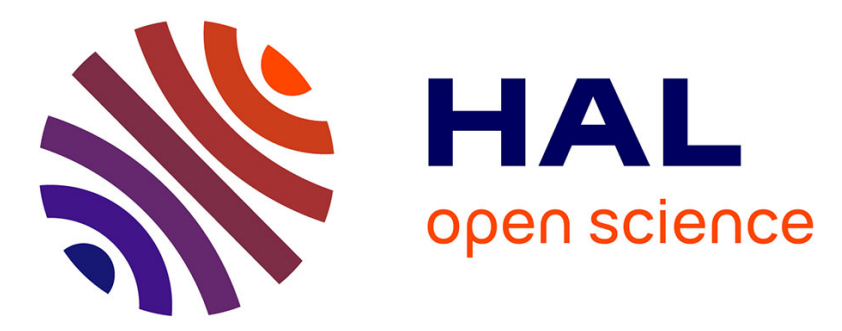

\title{
PS-b-PMMA/PLA blends for nanoporous templates with hierarchical and tunable pore size
}

Thi-Hoa Nguyen, Marylène Vayer, Christophe Sinturel

\section{To cite this version:}

Thi-Hoa Nguyen, Marylène Vayer, Christophe Sinturel. PS-b-PMMA/PLA blends for nanoporous templates with hierarchical and tunable pore size. Applied Surface Science, 2018, 427, Part B, pp.464470. 10.1016/j.apsusc.2017.08.160 . hal-02267755

\section{HAL Id: hal-02267755 \\ https://hal.science/hal-02267755}

Submitted on 11 Jan 2022

HAL is a multi-disciplinary open access archive for the deposit and dissemination of scientific research documents, whether they are published or not. The documents may come from teaching and research institutions in France or abroad, or from public or private research centers.
L'archive ouverte pluridisciplinaire HAL, est destinée au dépôt et à la diffusion de documents scientifiques de niveau recherche, publiés ou non, émanant des établissements d'enseignement et de recherche français ou étrangers, des laboratoires publics ou privés. 


\title{
PS-b-PMMA/PLA blends for advanced nano-lithographic templates
}

Thi-Hoa Nguyen, Marylène Vayer, Christophe Sinturel*

Interfaces, Confinement, Matériaux et Nanostructures (ICMN) CNRS-Université d'Orléans, UMR 7374 1B Rue de la Férollerie, C.S. 40059, 45071 Orléans Cedex 2, France

\begin{abstract}
Blends of poly(styrene)-block-poly(methyl methacrylate) (PS-b-PMMA) and poly(lactide) (PLA) were deposited in the form of thin films on the surface of modified silicon wafers and exposed to tetrahydrofuran (THF) vapor annealing. It was shown that in specific experimental conditions, a coreshell morphology consisting in cylinders with a PMMA shell and a PLA core, within a continuous matrix of PS, was formed. In this case, PLA naturally segregated in the core of the PMMA cylinders, minimizing the PS/PLA interaction, which constitutes the most incompatible pair (the interaction strength between the various components was confirmed in thin films of the corresponding polymer blends). Compared to other block copolymer/homopolymer blends described in the literature, this system exhibits unexpected high increase of the characteristic lengths of the system (center-to-center distance and diameter). This was attributed to a partial solubilization of the PLA in the PMMA corona (the two polymers are highly compatible), inducing an enhanced level of PS and PLA stretching caused by the strong repulsion between these two polymers. The selective extraction of the PLA yielded to porous domains with small dimensions $(6 \pm 2.5 \mathrm{~nm})$, reaching the performances that are currently attained in highly incompatible block polymers with low molecular weight. Further PMMA removal revealed a second porosity level, with higher
\end{abstract}


pores diameter and center-to-center distance compared to the neat PS-b-PMMA system. This work highlights how PS-b-PMMA, that currently represents one of the industrial standards nanoporous template precursors, can be modified in an easy and costless approach using PLA homopolymer addition.

Key words: thin films, homopolymer/copolymer blends, solvent annealing, sub-10 nm porosity, nanolithography 


\section{Introduction}

The phase behavior of block polymers can be notably modified by the addition of homopolymers. When the macrophase is avoided, i.e. when the homopolymer is incorporated into the existing domains, changes in the dimensions can arise (one of the domains is swollen) but also new morphologies can be formed. This has been carefully addressed by numerous studies, from a theoretical point of view [1-4] and experimentally demonstrated in the bulk [5-9] and in thin films [9-20]. Starting from a given block polymer composition that normally dictates the type of morphology at equilibrium, it is thus possible to tune the properties of the self assembly by homopolymer addition, expanding the possibility to generate various template geometries with tailored dimensions. From a practical point of view, this is particularly interesting in the field of the elaboration of nanoporous templates where a simple costless homopolymer addition would render possible a fine tuning of the morphology (instead of a cumbersome and costly library of block polymers with various dimensions and compositions). Among the various block polymer systems considered for applications within such approach, PS-b-PMMA currently represents the industrial standard [20-24]. Despite a relatively moderate incompatibility (preventing the possibility to obtain feature size in the sub-10 $\mathrm{nm}$ range unlike high $\chi$ materials [25]), the familiarity in the microelectronic industry with the two homopolymers, the relative ease of the polymer synthesis, the possibility to find solvent compatible with the industrial requirements, the improvement of the long range order and reduction of defects density obtained with the DSA approach have made PS-b-PMMA a very attractive system. For this polymer, it has been well demonstrated that homopolymer addition such as PMMA [10,14,15] or PEO [13] in a cylinder-forming PS-b-PMMA was able to modify the dimension of the domains formed. Interestingly, depending on the system composition and molar weight of the added homopolymer, new core/shell morphology could be formed and from such organization, Jeong et al.demonstrated the possibility to generate 
sub-10 nm porosity with selective extraction of the PMMA [11] or PEO [13]. In this work, we have examined the possibility to modify the morphology of a typical PS-b-PMMA system with PLA. Despite an abundant literature devoted to block polymer/homopolymer blends, such system has not been yet considered to our knowledge. Compared to other types of modifiers, PLA represents a material with a growing interest due to its renewable source and the ease of its selective degradation with dilute base, that would leave totally unaffected the PS and PMMA domains in contrast to PS-b-PMMA/PMMA or/PEO blends where the extraction of the PMMA would potentially result in surface reconstruction due to the PMMA block swelling. In addition, PLA displays higher level of incompatibility towards PS than PMMA, allowing for sharper behavior in comparison to PS-b-PMMA/PMMA(or even PS-bPMMA/PEO) system. Our purpose is to examine how small amounts of such affordable homopolymer can have a profound impact on established block polymer morphologies. The stability of the obtained morphologies upon solvent annealing has been examined. 


\section{Experimental}

\section{Materials and chemicals}

Poly(styrene) (PS), poly(lactide) (PLA), poly(methyl methacrylate) (PMMA) homopolymers and PS-b-PMMA, P(S-r-MMA) block polymers were purchased from Polymer Source Inc. TetraEthylOrthoSilicate (TEOS) and all used solvents were purchased from Sigma Aldrich and used as received. $\mathrm{Si}(100)$ substrates of $10 * 10 \mathrm{~mm} 2$ were cleaned by sonication in dichloromethane, methanol and distilled water for 10 min each.

\section{Thin films preparation}

PS-b-PMMA/PLA blend: a $10 \mathrm{mg} \cdot \mathrm{mL}^{-1}$ solution of PLA $\left(16 \mathrm{~kg} \cdot \mathrm{mol}^{-1}\right)$ in acetone or toluene was prepared and mixed in appropriate amounts to a $20 \mathrm{mg} \cdot \mathrm{mL}^{-1}$ solution of PS-b$\operatorname{PMMA}\left(101 \mathrm{~kg} \cdot \operatorname{mol}-1, \mathrm{f}_{\mathrm{PMMA}}(\mathrm{vol})=0.3\right)$ in toluene to prepare blends with homopolymer concentrations ( $\mathrm{vol} / \mathrm{vol} \%)$ of $1,5,10$ and $15 \%$ in the dry state (based on the density of each component). The resulting solution mixtures were agitated overnight before being deposited by spin coating $(2500 \mathrm{rpm})$ onto modified silicon wafers with a P(S-r-MMA) $\left(14 \mathrm{~kg} \cdot \mathrm{mol}^{-1}\right)$ brush on top (to prepare the modified substrates, a thin layer (approx. $10 \mathrm{~nm}$ ) of P(S-r-MMA) was firstly deposited onto clean silicon wafers, heated under vacuum at $170^{\circ} \mathrm{C}$ for $48 \mathrm{~h}$ and rinsed in toluene). Homopolymer/block polymer thin films with a thickness between 60 and $70 \mathrm{~nm}$ were obtained using this procedure (thicknesses were measured by imaging a scratched area in AFM tapping mode). After deposition, thin filmswere exposed at $25^{\circ} \mathrm{C}$ to THF vapors in a closed vessel $(150 \mathrm{~mL})$ containing $5 \mathrm{~mL}$ of THF for 5 and $10 \mathrm{~min}$. PS/PMMA/PLA blend:PS (67 kg· mol$\left.{ }^{-1}\right)$, PMMA $\left(30 \mathrm{~kg} \cdot \mathrm{mol}^{-1}\right)$, and PLA $\left(16 \mathrm{~kg} \cdot \mathrm{mol}^{-1}\right)$ 3/1/1 (weight fraction) ternary blends were prepared by mixing in appropriate amounts a toluene solution of PS $\left(10 \mathrm{mg} \cdot \mathrm{mL}^{-1}\right)$ with PMMA/PLA $\left(10 \mathrm{mg} \cdot \mathrm{mL}^{-1}\right)$ blend in acetone. 


\section{Atomic force microscopy (AFM)}

AFM in the tapping mode was carried out in air at room temperature with a Nanoscope III from Digital Instruments Corp. Silicon cantilevers Tap300 from Budget Sensors with integrated symmetrical pyramidal tips $(15 \mu \mathrm{m}$ high) with no Al coating backside, a nominal spring constant of $42 \mathrm{~N} . \mathrm{m}^{-1}$ and a resonance frequency between 300 and $400 \mathrm{kHz}$ were used. All the displayed AFM images are height images taken in tapping mode. Characteristic lengths (diameter and center-to-center distance) were extracted from 2D line cut. Each dimension provided is the result of multiple measurements with a typical standard deviation of $2.5 \mathrm{~nm}$ taken as uncertainty (error bar on Fig. 3).

\section{Thickness measurement upon swelling}

The evaluation of the solvent/polymer interaction strength was achieved by exposing each polymer thin films (separately) to solvent vapors. For that purpose, a closed PTFE box with a cover equipped with a sealed optical glass window was used. The swelling ratio $\mathrm{d} / \mathrm{d} 0$ is defined by the ratio between the thickness (d) of the film at time (t) and the thickness (d0) at time $(\mathrm{t}=0)$. The film thickness was measured continuously using an interference-based film thickness measurement system (F20, Filmetrics) until the thickness reach a plateau (typically 5-10 min). The film was illuminated with a white light source at a normal incidence. The intensity of the reflected light was recorded as a function of the incident wavelength and was fitted using a model taking into account the interferences of the light waves reflected from the upper and lower surfaces of the film at different light wavelengths.

\section{Selective removal of the component}

PLA was selectively degraded by placing the sample in a0.5 M sodium hydroxide solution containing 40/60 (by volume) methanol/water for $30 \mathrm{~min}$. After being removed from the 
solution, the samples were washed with a 40/60 (by volume) methanol/water solution. PMMA was selectively removed by exposing the thin films to UV radiation $(254 \mathrm{~nm})$ during $60 \mathrm{~h}$ (lamp power: $0.10 \mathrm{~mJ} / \mathrm{s}$ ) and further immersion of the irradiated films into concentrated acetic acid for 20 min and finally rinsed in distillated water.

\section{Inorganic replication of the porous films}

The silica precursor solution (TEOS:H2O:EtOH:HCl) with a molar proportion of 1:5.5:21:0.005 was prepared by mixing $26.5 \mathrm{~mL}$ EtOH, $1 \mathrm{~mL}$ deionised water, $1.25 \mathrm{~mL} \mathrm{HCl}$ $0.1 \mathrm{M}$ and $5 \mathrm{~mL}$ TEOS and stirring at least during $16 \mathrm{~h}$ at room temperature. The porous PS films were immerged in the solution allowing for the infiltration of the porosity by the liquid silica precursors [26]. After withdrawal, samples were then heated at $450{ }^{\circ} \mathrm{C}$ during $5 \mathrm{~min}$ to provoke the precursor condensation and the elimination of the polymer template to yield the silica replicas. Depending on the deposition conditions (withdrawal speed), the formation of a dense silica roof layer above the porous replica could be obtained [27]. This was exploited to prepared mechanically robust samples for the cross sectional views. 


\section{Results and discussions}

\section{Film morphology as function of homopolymer addition}

In this section, we examine the influence of the homopolymer (PLA) content on the structuration of the block polymer (PS-b-PMMA). For that purpose, PS-b-PMMA (101 $\left.\mathrm{kg} \cdot \mathrm{mol}^{-1}, \mathrm{f}_{\mathrm{PMMA}}=0.3\right) / \mathrm{PLA}\left(16 \mathrm{~kg} \cdot \mathrm{mol}^{-1}\right)$ blends were firstly prepared by mixing a solution of PS-b-PMMA in toluene with a solution of PLA in acetone. The homogenous mixture was then spin-coated on silicon wafer. Fig. 1 shows the surface morphology of the resulting films, as a function of the homopolymer content. Surface topography is shown for the as casted samples and after 5 and 10 min of solvent vapor exposure. The absence of macroscopic phase segregation suggests that the incorporation of the PLA is homogenous in the studied range of the composition (up to $15 \%$ ). We observed that the incorporation of the homopolymer in the block polymer was dependent on the deposition conditions. Fig. S1 (Supplementary Materials) shows several examples of as spun morphologies with homogenous and heterogeneous dispersions. Using chlorobenzene as the solvent for both the block polymer and the homopolymer led to a macroscopic phase separation (Fig. S1c and S1f). In contrast, solvent mixture (toluene/THF and toluene/acetone) promoted a homogenous dispersion of the homopolymer in the block polymer self-assembled pattern (Fig. S1a-b and Fig. S1d-e). In fact, we will demonstrate later that the PLA is incorporated in the minor PMMA domains (as one can already deduce from the clear increase in size of the segregated phases observed in Fig. 1). The absence of macrophase separation in the blend can be explained on the basis of the miscibility properties of the components. Acetone or THF, which are good solvents for PMMA and PLA (but not for PS), will promote the segregation of these two components, forming micelles like structures (with a PS corona) at nanoscopic scale as the solvent evaporates. As observed in Fig. 1, as spun neat PS-b-PMMA thins films do not exhibit clear 
ordered nanostructuration, due the fast evaporation of the solvent and the rather low chemical incompatibilityof the PS and PMMA blocks.

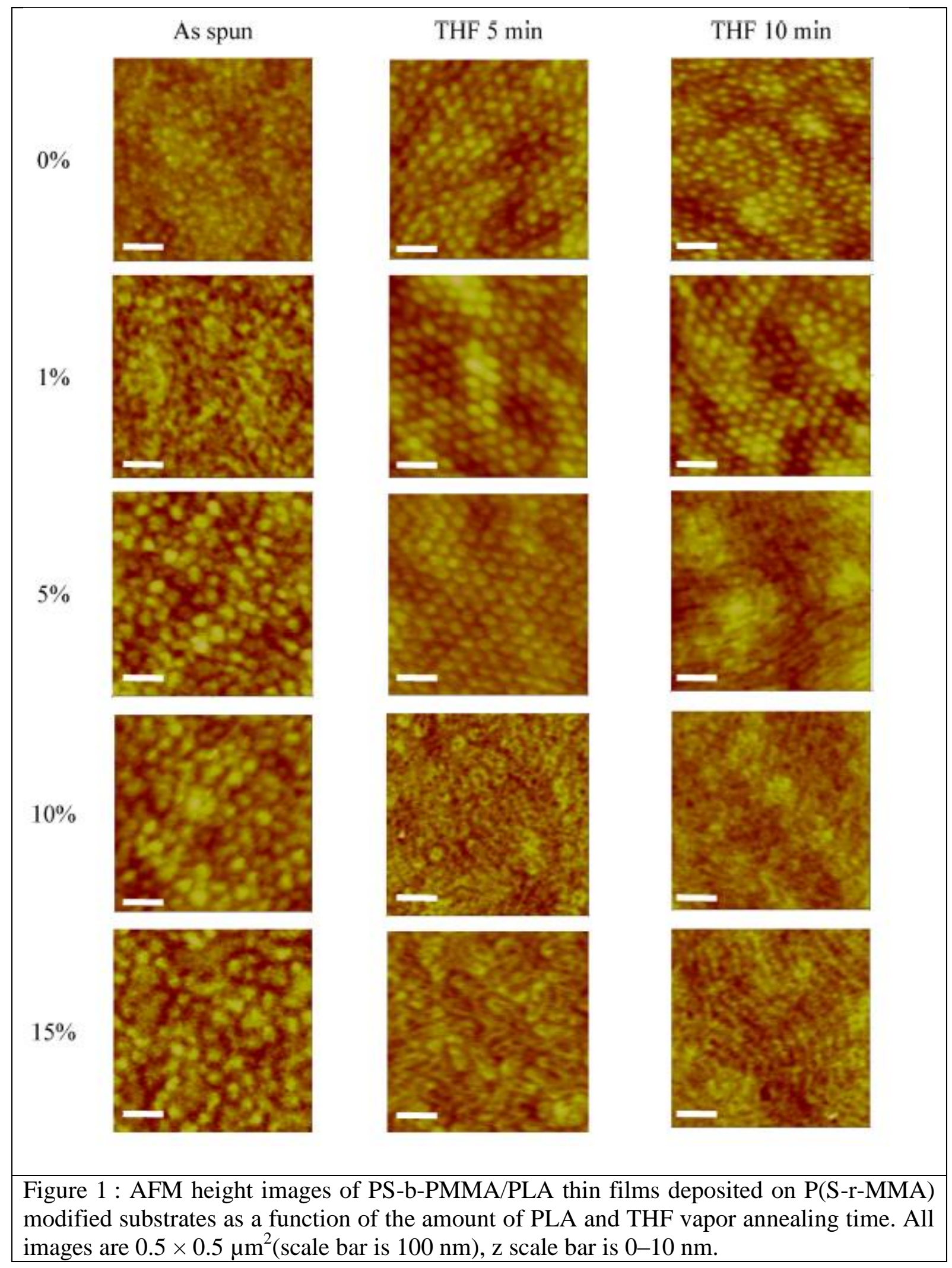


Adding PLA in the system does not improve the order in the as spun state, but clearly the microphase separation is enhanced as judged by the increase in contrast of the images (particularly after 5\%). After exposure to solvent vapors, the nanostructuration is improved. Hexagonal array of dots or fingerprint morphologies are formed depending on the exposure time and amount of PLA added. The formation of the hexagonal array is driven by the natural properties of the PS-b-PMMA to self-assemble into such morphology. However, despite the use of a neutralized substrate that normally promotes the formation of a perpendicular orientation of the PMMA domains, [28] the presence of PLA favored the formation of parallel orientation. When the proportion of PLA is above a given threshold (between 1 and 5\% for 10 min exposure; 5 and $10 \%$ for $5 \mathrm{~min}$ ), the presence of the latter drives the orientation of the domains towards a parallel orientation. This suggests that the neutralized substrate is specific for PS and PMMA composition but not for PLA. We, and others, have already demonstrated that such transition is strongly driven in the swollen state, by the affinity of the domains towards the interfaces.[29,30] When polymers display different swelling extent they will exhibit different response towards a surface field even if the surface energy of the polymers is similar. The swelling extent of PS, PLA and PMMA measured under THF vapors (same conditions than Fig. 1) showed that PLA swells slightly more than the other counterparts (1.8 for PLA vs 1.6 for PS and PMMA) indicating that the delicate surface energy balance between PS/PMMA domains and the interface favoring the perpendicular orientation is prone to perturbation in presence of PLA. The characterization of the actual morphology, as well as the localization of the polymer phases was carried out using specific polymer extraction (hydrolysis under mild alkaline solution for PLA and UV exposure followed by acetic acid extraction for PMMA). The resulting porous polymer film was examined by AFM and subjected to replication in order to assess the internal structuration of the film and fully confirm the morphology adopted [26]. This is shown in Fig. 2 where the two typical 
nanostructurations (dots in Fig. 2a and fingerprint in Fig. 2f) were successively exposed to

PLA removal, PMMA removal and replication of the resulting porosity.

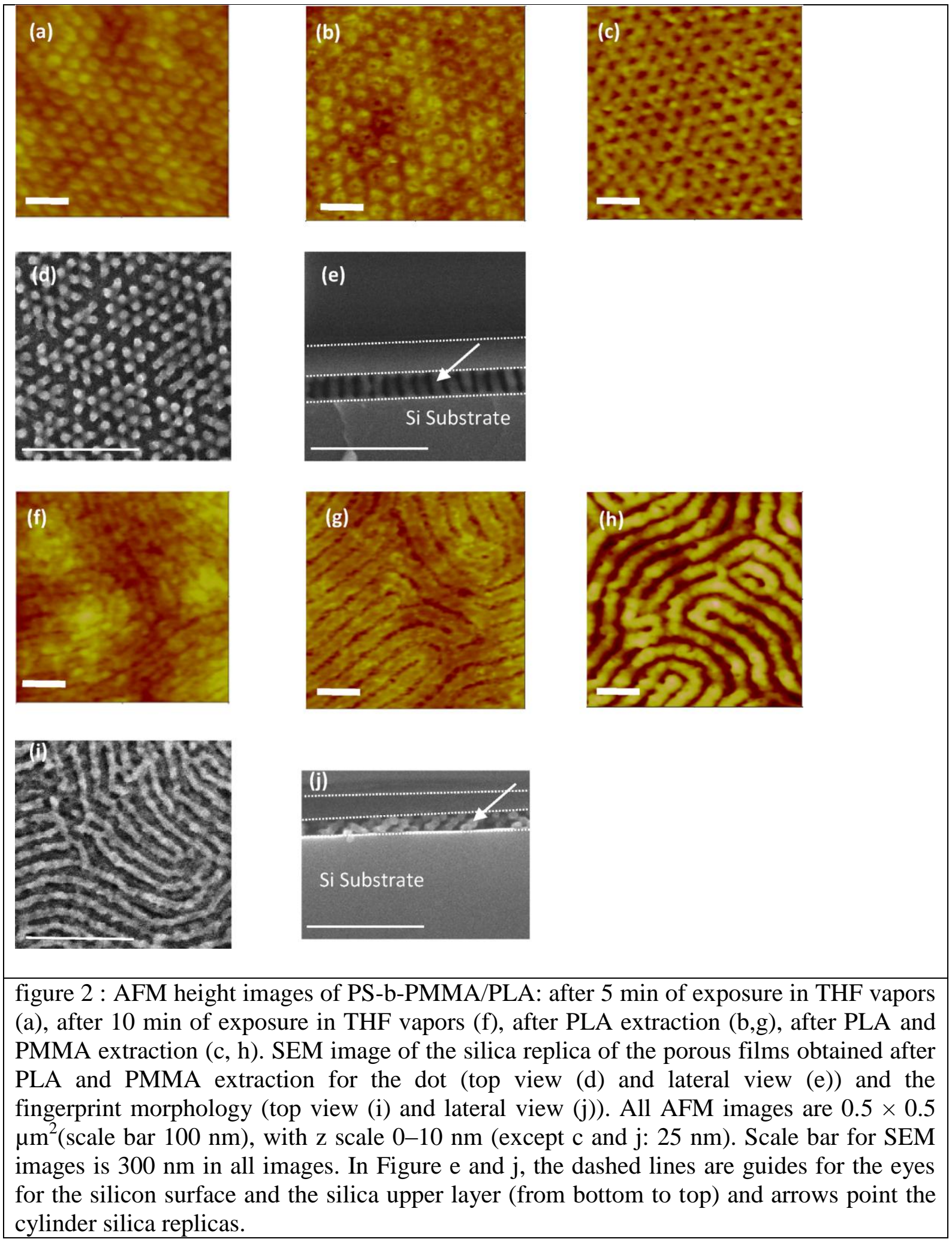


In the case of the dots morphology, the first PLA extraction forms small depressions located in the center of the circular domains, indicating that the PLA is located in the middle of the PMMA domains (Fig. 2b). Further extraction of the PMMA domains enlarges the pores diameters (Fig. 2c). The final resulting porosity (after PLA and PMMA removal) was replicated by infiltration with sol-gel precursors followed by a brief thermal treatment in order to provoke the condensation of the precursors and the pyrolysis of the polymer phase. The top (Fig. 2d) and side view (Fig. 2e) of the obtained replica reveal an array of perpendicular pillars (covered by an upper layer in the case of the cross sectional view to ensure the mechanical stability of the replica upon fracture - see experimental part), indicating that the parent porosity and therefore, the initial morphology, can be depicted as an array of vertical cylinders. For the fingerprint morphology, the selective removal of PLA (Fig. 2g), followed by the PMMA extraction (Fig. 2h) indicates that the PLA is similarly located in the center of the PMMA. The replication confirmed the presence of parallel cylinders as seen on the top (Fig. 2i) and side (Fig. 2j) views. For this latter, the observed structure can be described as an array of collapsed solid cylinders in contact, resulting from the elimination of the continuous phase.

\section{Analysis of the characteristic dimensions of PS-b-PMMA/PLA blends.}

Naturally, the characteristic dimensions of the features formed by the self-assembly process increased with the amount of PLA added in the blends, as a direct consequence of the incorporation of the PLA into the PMMA domains. 


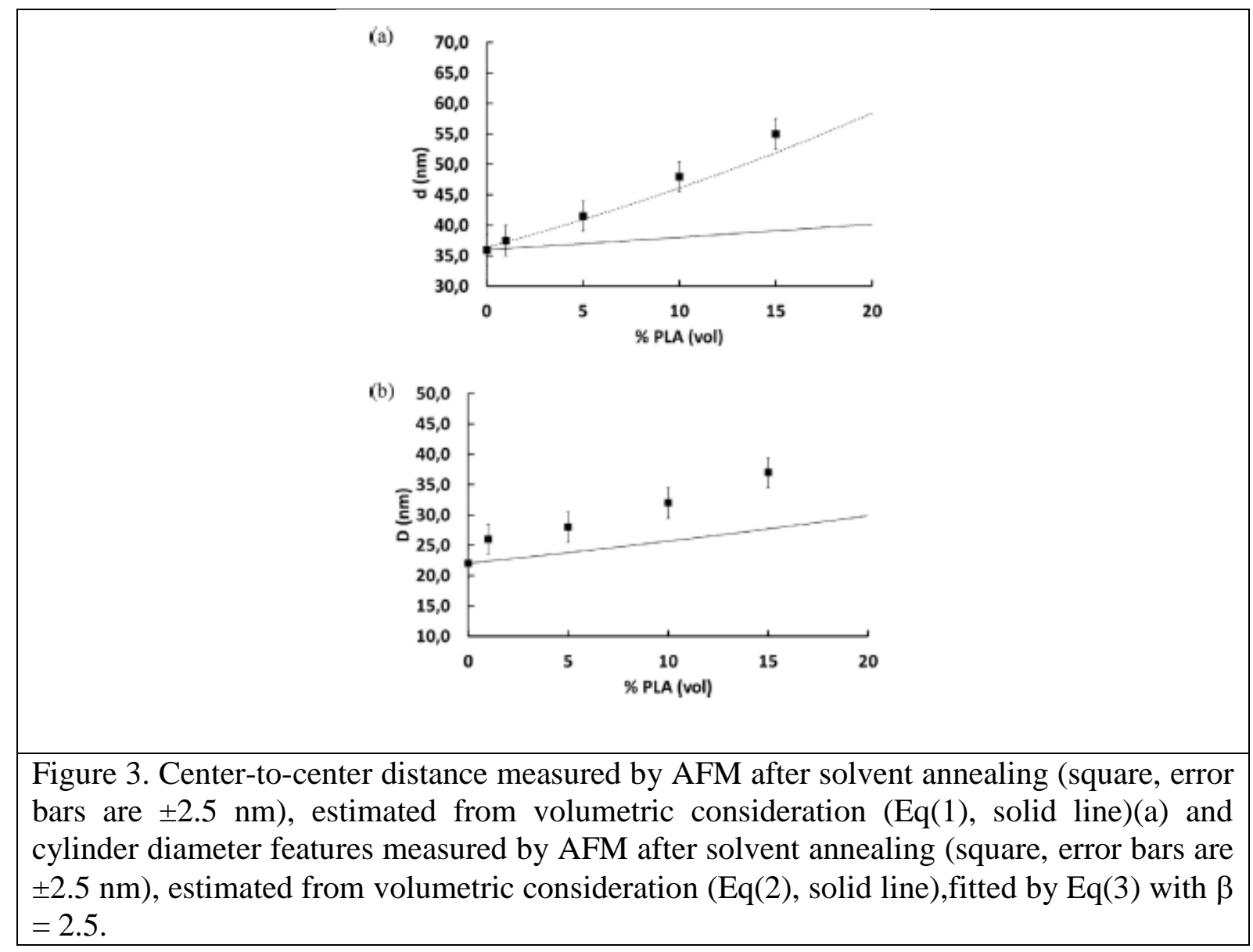

From the AFM images, we measured the variation of the center-to-center distance (d) and cylinder diameter (D) with the PLA content (Fig. 3). As expected and already demonstrated by others [10-14] increased amount of homopolymer leads to increased values of the characteristics distances of the system. As demonstrated by the selective extraction of the homopolymer, localization of the PLA phase occurs in the center of the PMMA blocks which corresponds to the so-called "dry-brush" regime described by the seminal work of Hashimoto [5]. In this specific case, the conformation of the two blocks (PS, PMMA) and the junction density (or average area per junction) at interface should remain unaffected by the homopolymer addition (this is actually rigorously true only in flat interface, but can be approximated in the case of cylindrical features where the dimension increase is small).In these conditions, simple volumetric considerations assuming a core-shell cylinders of PLA 
(core) and PMMA (shell) allow to calculated the center-to-center distance (d) and diameter

(D) of the resulting cylindrical domains as follows:

$$
\begin{aligned}
& d=\frac{d_{0}}{(1-\varphi)^{0.5}} \\
& D=D_{0} \sqrt{1+\frac{\varphi}{f(1-\varphi)}}
\end{aligned}
$$

where $d_{0}$ and $D_{0}$ are respectively the center-to-center and the diameter of the PMMA cylinders in the neat PS-b-PMMA film, $\mathrm{f}$ is the volume fraction of the PMMA bloc in the PSb-PMMA copolymer and is the volume fraction of the PLA added. It is important to note that this estimation, based on such simple volumetric considerations derived from the "dry brush" model, normally represents the highest increase value that can be achievable. Indeed, in the "wet-brush" model, addition of homopolymer tends to produce lower distance increase (eventually a decrease).This latter phenomenon is well documented for A-B block copolymer mixed with low molecular weight of $\mathrm{A}$ and/or B block and is commonly attributed to the necessity for the non-swollen block to contract in order to accommodate the change in junction density at the interface produced by the swelling of the other block (incompressibility requirement) [5-7,31]. This is why distance increase in the "dry brush" regime is generally higher than in the "wet brush" configuration. However, as shown in Fig. 3, both center-tocenter distances and diameters evaluated using this simple volumetric consideration are still underestimated, indicating that a simple picture of PLA being localized in the center of the PMMA domains without changing the conformation of the PS and PMMA blocks is not realistic. Higher level of chain stretching needs to be introduced to account for such behavior. In our case, even if the localization of the PLA has been clearly demonstrated, a partial PLA partition inside the PMMA phase, producing a swollen corona of PMMA, cannot be ruled out. Because PS and PLA are much more incompatible that PS and PMMA, a strong increase of the effective Flory-Huggins parameters between PS and (PMMA+PLA) phases would occur in this case, causing the chains to stretch more in both domains. Such trend has been already 
reported, through the observation that distance in the "dry brush" regime was following

empirical relationship of the form: $\quad d=\frac{d_{0}}{(1-\varphi)^{A}}$

(3) where $\beta$ takes values $>0.5$ leading to increased values of $d$. For asymmetric compositions, a value of $=0.83$ has been reported by Stuen et al. [14] for a PS-b-PMMA/PMMA in the "dry brush" regime. In our case the best fit occurs for $=2.5$ suggesting a more pronounced stretching effect, in good agreement with the strong incompatibility of the PS and PLA chains. (It is important to note that the stretching of the blocks (and consequently the porosity dimension), could be influenced by the type of solvent used in the annealing step.) In order to confirm the PS/PMMA/PLA interactions, we have examined the behavior of the corresponding homopolymer ternary blend.

\section{Segregation strength in ternary homopolymer blends}

Ternary blends of PS $\left(67 \mathrm{~kg} \cdot \mathrm{mol}^{-1}\right)$, PMMA $\left(30 \mathrm{~kg} \cdot \mathrm{mol}^{-1}\right)$, et PLA $\left(16 \mathrm{~kg} \cdot \mathrm{mol}^{-1}\right)$ were prepared by mixing a toluene solution of PS with PMMA/PLA blend in acetone (PS/PMMA/PLA 3/1/1 wt/wt).
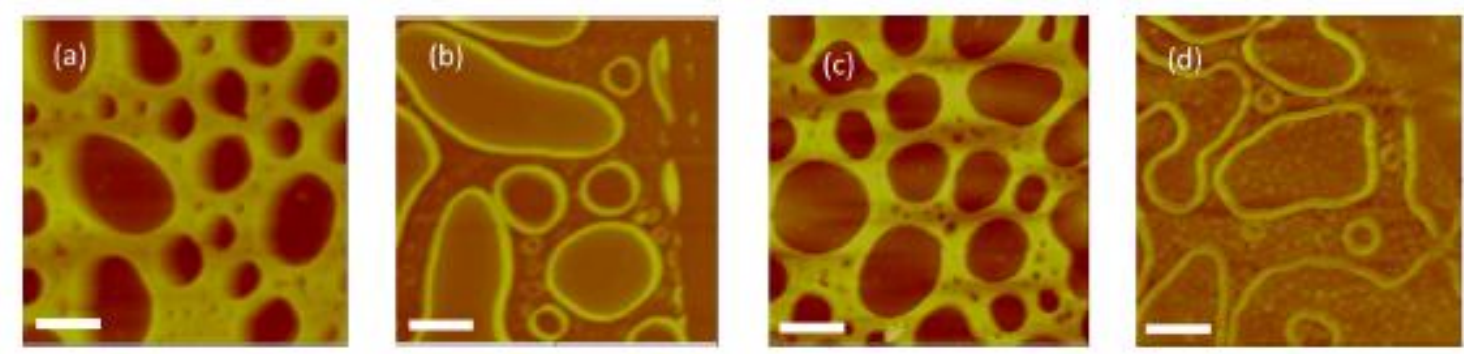

Fig. 4. AFM height images of PS/PMMA/PLA blends after spin coating (a), after selective PS extraction with cyclohexane (b), after selective PLA hydrolysis (c), after PS and PLA removal (d). All images are $5 \times 5 \mu \mathrm{m}^{2}$ (scale bar is $\left.1 \mu \mathrm{m}\right)$, with z scale $0-250 \mathrm{~nm}$. 
As observed in Fig. 4a, the as casted film exhibits a macrophase separated morphology, with important height difference between the segregated phases that can be related to different rates of drying as already proposed in previous work [32]. The film topography can be described as a continuous layer, with segregated domains of lower elevation (depression). Again, a selective extraction of PS(with cyclohexane) and PLA (hydrolysis) allowed us to clarify the polymer repartition in the film. As seen in Fig. $4 \mathrm{~b}$, the continuous phase is removed by cyclohexane, thus assigned to PS. On the other hand, the depressions are removed by hydrolysis and then ascribe to PLA (Fig. 4c). PMMA localization is revealed by the successive extraction of PS and PLA (Fig. 4d). This results in the formation of vertical walls creating hollow structures, indicating that the PMMA is located at the interface PS/PLA. This behavior can be explained on the basis of the interaction strength for these components. This can be deduced from the known value of the Flory-Huggins parameters of the PS/PLA and PS/PMMA pairs, respectively 0.13 [33] and 0.04 [34] at $25^{\circ} \mathrm{C}$, showing interaction strength in the order PS/PLA < PS/PMMA. Although reliable Flory-Huggins value of the PLA/PMMA is not available, several work [35-37] reported the good compatibility of this system that can reasonably place the interaction strength of the PLA/PMMA pair above the values of the two others (PS/PLA < PS/PMMA < PLA/PMMA). Consequently, the PMMA will locate at the interface PS/PLA, screening the interaction between those two polymers which constitute the most incompatible pair. This behavior corroborates the results obtained in the PS-bPMMA/PLA system where the PLA naturally segregates in the core of the PMMA cylinders, minimizing the PS/PLA interaction. A schematic view of the blend morphology is provided in Fig. 5 (the volume fraction estimated form such schematic view, using the dimensions and high of the domains extracted from the AFM measurement was found to be in good agreement with the volume fraction of the ternary blend). 


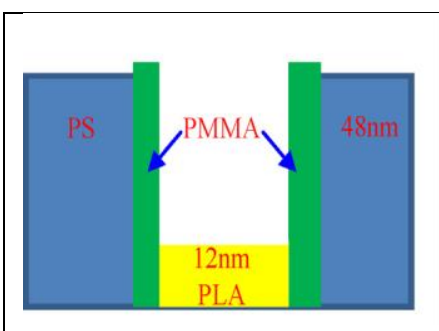

(a)

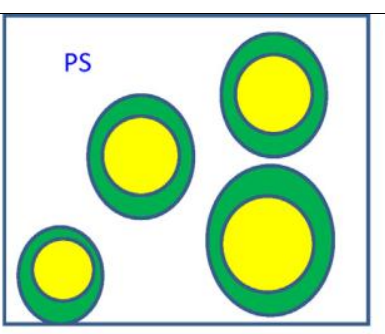

(b)

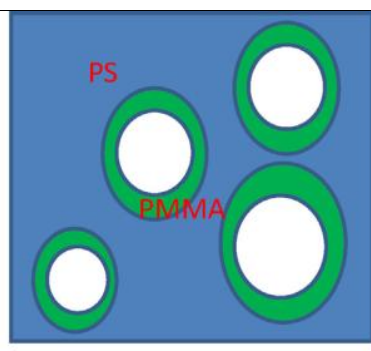

(c)

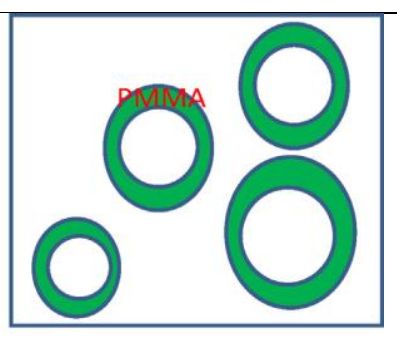

(d)

Figure 5: Schematic representation of the morphology (cross sectional view) of the PS/PMMA/PLA ternary blend (a) deduced from the specific extraction of PS (b, top view), PLA(c, top view), PS and PLA (d, top view). PS is in blue, PLA in yellow, PMMA in green. (For interpretation of the references to colour in this figure legend, the reader is referred to the web version of this article.)

\section{Hierarchical porosity in PS-b-PMMA/PLA blends}

The core shell morphology obtained in PS-b-PMMA/PLA blends is a very interesting behavior since the selective extraction of PLA and PMMA can provide two levels of porosity in the material. The selective extraction of PLA (i.e. only the center of the cylinders) leads to a porosity in a much smaller dimension than what can be normally reached with PS-b-PMMA ( $\sim 15 \mathrm{~nm}$ minimum due the relative moderate incompatibility of the PS and PMMA blocks). In our work, we have estimated this porosity to be $6 \pm 2.5 \mathrm{~nm}$ in the blend containing $5 \%$ of PLA, which corresponds to the level that are currently obtained using highly incompatible polymers, with increased segregation strength [25]. However, it is worth noting that the domain density increase which is normally attained with feature size reduction is here counterbalanced by the increase of the inter-domain spacing that results from the homopolymer addition. This approach, which is thus not ideal for the generation of templates with ultrahigh features density, is much in line with current technology such as contact hole shrink where the main objective is the domain size reduction [38]. From the application standpoint, we anticipate that this method could be interestingly combined with the directed self-assembly (DSA) approach [39,40] in order to favor increased long range ordering and lower defectivity. In addition, increase of the characteristic lengths could find interesting 
applications in templates for nanopatterning where particle-particle distance should be sufficiently high to suppress coupling between particles, like in the case of magnetic particles [41].Further extraction of the PMMA phases led to a second level of porosity, with pores diameters larger compared to the situation of the neat PS-b-PMMA. We observed that the molar mass of PLA was determinant to obtained this core-shell morphology. The segregation effect was herein observed for a PLA molar mass of16 $\mathrm{kg} \cdot \mathrm{mol}-1$. Lower molar mass $(6,5$ $\mathrm{kg} \cdot \mathrm{mol}-1)$ resulted into hexagonally packed cylinders with no evidence of segregation of a PLA phase in the center on the PMMA cylinders. However, increased cylinder size and center-to-center distance suggests the incorporation of the PLA. Higher molar mass (48 $\mathrm{kg} \cdot \mathrm{mol}-1)$ resulted into a macroscopic separation of the components. These results are in line with previous observation in PS-b-PMMA/PMMA [6] blends where the core/shell morphology was only obtained for PMMA molar weight close to the one of the PMMA block, whereas values lower and higher respectively led to complete solubilization and macroscopic phase separation.

\section{Conclusion}

In this work we have examined the morphology of thin films of PS-b-PMMA/PLA blends. For a PS-b-PMMA with a standard molar weight $(101 \mathrm{~kg} \cdot \mathrm{mol}-1)$ we examined the influence of the type of solvent used for the deposition, the concentration and molar weight of PLA as well as the behavior of the obtained films upon solvent vapor annealing. In some conditions, hexagonally packed core(PLA)-shell(PMMA) cylinders, oriented perpendicularly to the substrate, within a continuous matrix of PS were formed. This allowed the formation of porous domains with extremely small dimensions $(6 \pm 2.5 \mathrm{~nm})$ after selective extraction of the PLA, reaching the performances that is currently attained in highly incompatible block polymers with low molecular weight. Such core/shell morphology was obtained when PLA 
segregated in the core of the PMMA cylinders, minimizing the PS/PLA interaction, which constitutes the most incompatible pair. This result originates not only from the miscibility properties of the three polymers which are driven by their relative incompatibility but also by the solvent used for the deposition and the molar weight. Compare to other block copolymer/homopolymer blends described in the literature, this system exhibits unexpected high increase of the characteristic lengths of the system (center-to-center distance and diameter). This was attributed to a partial solubilization of the PLA in the PMMA corona (the two polymer are highly compatible), inducing an enhanced level of PS and PLA stretching caused by the strong repulsion between these two polymers. Another difference with similar system already described in the literature (PS-b-PMMA/PMMA or/PEO) relies in the mode of extraction of the center part of the cylinders. Because it implies a selective degradation of the PLA, it leaves totally unaffected the PS and PMMA domains in contrast to a solvent extraction method that would potentially result in surface reconstruction of the surface.

\section{Acknowledgments}

We thank Joël Puibasset (ICMN) for fruitful discussions and Annie Richard (University of Orléans, CME) for SEM observations.

\section{References}

[1] R. Choksi, X. Ren, Phys. D 203 (2005) 100.

[2] A.E. Likhtman, A.N. Semenov, Macromolecules 30 (1997) 7273.

[3] M.W. Matsen, Macromolecules 28 (1995) 5765.

[4] Y. Huang, H. Liu, Y. Hu, Macromol. Theory Simul. 15 (2006) 321.

[5] H. Tanaka, H. Hasegawa, T. Hashimoto, Macromolecules 24 (1991) 240.

[6] T. Hashimoto, H. Tanaka, H. Hasegawa, Macromolecules 23 (1990) 4378. 
[7] H. Tanaka, T. Hashimoto, Macromolecules 24 (1991) 5713.

[8] K.I. Winey, E.L. Thomas, L.J. Fetters, Macromolecules 24 (1991) 6182.

[9] T.A. Mykhaylyk, O.O. Mykhaylyk, S. Collins, I.W. Hamley, Macromolecules 37(2004) 3369.

[10] U. Jeong, D.Y. Ryu, J.K. Kim, D.H. Kim, X. Wu, T.P. Russell, Macromolecules 36(2003) 10126.

[11] U. Jeong, H.-C. Kim, R.L. Rodriguez, I.Y. Tsai, C.M. Stafford, J.K. Kim, C.J. Hawker, T.P. Russell, Adv. Mater. 14 (2002) 274.

[12] U. Jeong, D.Y. Ryu, J.K. Kim, D.H. Kim, T.P. Russell, C.J. Hawker, Adv. Mater. 15(2003) 1247

[13] U. Jeong, D.Y. Ryu, D.H. Kho, D.H. Lee, J.K. Kim, T.P. Russell, Macromolecules $36(2003) 3626$.

[14] K.O. Stuen, C.S. Thomas, G. Liu, N. Ferrier, P.N. Nealey, Macromolecules 42(2009) 5139.

[15] J. Peng, X. Gao, Y. Wei, H. Wang, B. Li, Y. Han, J. Chem. Phys. 122 (2005) 114706.

[16] S.H. Kim, M.J. Misner, T.P. Russel, Adv. Mater. 16 (2004) 2119.

[17] R. Guo, H. Huang, B. Du, T. He, J. Phys. Chem. B 113 (2009) 2712.

[18] C.G. Gamys, A. Vlad, O. Bertrand, J.-F. Gohy, Macromol. Chem. Phys. 213 (2012) 2075.

[19] V. Mishra, S. Hur, E.W. Cochran, G.E. Stein, G.H. Fredrickson, E.J. Kramer, Macromolecules 43 (2010) 1942.

[20] D.U. Ahn, E. Sancaktar, Soft Matter 4 (2008) 1454.

[21] X. Chevalier, C. Nicolet, R. Tiron, A. Gharbi, M. Argoud, J. Pradelles, M. Delalande, G. Cunge, G. Fleury, G. Hadziioannou, C. Navarro, J.Micro/Nanolithogr. MEMS MOEMS. 12 (2013) 031102. 
[22] I.A. Zucchi, E. Poliani, M. Perego, Nanotechnology 21 (2010) 185304.

[23] H. Tsai, J.W. Pitera, H. Miyazoe, S. Bangsaruntip, S.U. Engelmann, C.-C. Liu, J.Y.

Cheng, J.J. Bucchignano, D.P. Klaus, E.A. Joseph, D.P. Sanders, M.E. Colburn,

M.A. Guillorn, ACS Nano 8 (2014) 5227.

[24] Y.-S. Sun, C.-T. Wanga, J.-Y. Lioub, Soft Matter 12 (2016) 2923.

[25] C. Sinturel, F.S. Bates, M.A. Hillmyer, ACS Macro Lett. 4 (2015) 1044.

[26] T.H. Nguyen, M. Vayer, D. Grosso, H. Amenitsch, C. Sinturel, J. Phys. Chem. C116 (2012) 5295 .

[27] M. Faustini, M. Vayer, B. Marmiroli, M.H. Hillmyer, H. Amenitsch, C. Sinturel, D. Grosso, Chem. Mater. 22 (2010) 5687.

[28] H. Kang, G.S.W. Craig, E. Han, P. Gopalan, P.F. Nealey, Macromolecules 45(2012) 159.

[29] T. Ghoshal, A. Chaudhari, C. Cummins, M.T. Shaw, J.D. Holmes, M.A. Morris, Soft Matter 12 (2016) 5429.

[30] M. Vayer, M.A. Hillmyer, M. Dirany, G. Thevenin, R. Erre, C. Sinturel, Thin Solid Films 518 (2010) 3710.

[31] N. Torikai, N. Takabayashi, I. Noda, S. Koizumi, Y. Morii, Y. Matsushita, Macromolecules 30 (1997) 5698.

[32] S. Walheim, M. Böltau, J. Mlynek, G. Krausch, U. Steiner, Macromolecules 30 (1997) 4995.

[33] A.S. Zalusky, R. Olayo-Valles, J.H. Wolf, M.A. Hillmyer, J. Am. Chem. Soc. 124 (2002) 12761.

[34] T.P. Russell, R.P. Hjelm, P.A. Seeger, Macromolecules 23 (1990) 890.

[35] B. Imre, K. Renner, B. Pukánszky, eXPRESS Polym Lett. 8 (2014) 2.

[36] G. Zhang, J. Zhang, S. Wang, D. Shen, J. Polym. Sci. Part B: Polym. Phys. 41(2003) 23. 
[37] A. Bouzouita, C. Samuel, D. Notta-Cuvier, J. Odent, F. Lauro, P. Dubois, J.M. Raquez, J. Appl. Polym. Sci. 133 (2016) 43402.

[38] I. Servin, R. Tiron, A. Gharbi, M. Argoud, K. Jullian, G. Chamiot-Maitral, P.Pimenta Barros, X. Chevalier, J. Belledent, X. Bossy, S. Moulis, C. Navarro, G.Cunge, S. Barnola, M. Asai, C. Pieczulewski, Jpn. J. Appl. Phys. 53 (2014)(06JC05-1/6).

[39] M.A. Morris, Fabrication Microelectron. E. 132 (2015) 207.

[40] H. Hu, M. Gopinadhan, C.O. Osuji, Soft Matter 10 (2014) 3867.

[41] D. Kechrakos, K.N. Trohidou, Phys. Rev. B 58 (1998) 12169. 